\title{
Searching the core of emergency medicine
}

\author{
A. M. Mørcke ${ }^{1}$, G. Wichmann-Hansen ${ }^{1}$, D. Guldbrand-Nielsen ${ }^{1}$, E. Tønnesen $^{2}$ and B. EikA ${ }^{1}$ \\ ${ }^{1}$ Unit of Medical Education, Aarhus University, and ${ }^{2}$ Department of Anaesthesiology, Aarhus University Hospital, Aarhus, Denmark
}

Background: The purpose of this study was to test whether focus groups involving medical students, house officers, senior doctors, and nurses could identify an undergraduate emergency medicine core curriculum.

Method: From May 2001 to January 2002, we interviewed 12 homogenous focus groups within all 88 participants. Three focus groups were composed of medical students; three of house officers, three of senior doctors, and three focus groups were composed of nurses. Each interview lasted $2 \mathrm{~h}$. Interviews were recorded, transcribed, and analysed using qualitative methods.

Results: The focus groups suggested and discussed in all 196 objectives. Students, physicians, and nurses agreed that newly graduated physicians should master history taking, 21 clinical disorders, 15 practical skills, interpretation of two diagnostic tests, two general diagnostic skills, and two leadership skills. Apart from these 43 core objectives, disagreement was substantial. Participants gave very different priorities to commu- nication, knowledge about clinical disorders, practical clinical skills, leadership, and 'the art of medicine'.

Conclusion: In conclusion, focus groups could identify an emergency medicine core curriculum. However, participants had very different perspectives on the curriculum. Focus groups could be one very practicable part of seeking consensus on what is core and securing local roots and ownership to an undergraduate emergency medicine curriculum before and during implementation.

Accepted for publication 22 September 2003

Key words: Curriculum; emergency medicine; focus groups; undergraduate medical education.

C) Acta Anaesthesiologica Scandinavica 48 (2004)
$\mathrm{T}$ HE core curriculum concept was introduced as a strategy to overcome the overload of medical students with factual information $(1,2)$. Core includes learning objectives or outcomes required by all students, whereas electives allow students in-depth studies of areas of particular interest to them. In 1971, the British General Medical Council recommended that approximately two-thirds of the undergraduate curriculum should be made up by compulsory elements leaving one-third of the total curriculum to electives $(1,2)$. Recently, the World Federation for Medical Education stated that medical schools must define learning objectives, and that the defined objectives must relate to students' postgraduate training, and should be based on inputs from a wider range of stakeholders (3). A systematic and optimal curriculum design process therefore involves a wide range of stakeholders, obtains balance between core and electives, and links objectives to postgraduate training.

In this context of core curriculum design, emergency medicine is of particular interest. Emergency medicine implicates a combination of theory, skills, ethics, and personal qualifications and contains learn- ing objectives that should be mastered by any doctor. Competence in the field is further developed during internship. This makes it interesting to decide which objectives are basic. The decision of what to include as core objectives is not a matter-of-course. Within the domain of undergraduate emergency medicine, medical schools, associations, and experts differ considerably in what they include in the core (4-8). They differ in the total number of objectives included, as well as in which objectives they include. In Denmark and other Scandinavian countries emergency medicine is not an official specialty. This also increases the number of potential stakeholders. At the time of the interviews, we did not offer an emergency medicine course at the University of Aarhus.

The purpose of this study was to test, whether focus group interviews can be feasibly applied to develop undergraduate emergency medicine core objectives incorporating views of different stakeholders familiar with competencies expected from newly graduated physicians. We also explored stakeholders' experiences and attitudes toward learning objectives. 


\section{Method}

The focus group method is a research technique collecting data through group interaction on a topic determined by the researcher (9). As other qualitative methods, the focus group method permits researchers to study questions in-depth without being constrained by predetermined categories of analysis, and produces a wealth of detailed information about a smaller number of people (10). Focus group interviews suited our purpose well, because one aim of the study was to explore stakeholders' experiences and attitudes toward learning objectives. Focus groups provided us with data on what participants thought about learning objectives, how they thought about it, and why they thought the way they did.

In the period 8 May 2001-22 January 2002, we interviewed 12 homogenous focus groups within all 88 house officers (HOs), senior doctors with $\mathrm{HOs}$ working as their 'front line', nurses with HOs on call, and medical students (Table1). Participants were sampled purposefully from Aarhus University, the university hospital, and local hospitals. Doctors and nurses represented a range of specialties. Two of the nurses were ward managers. Two of the senior doctors were consultants, the remainder specialist registrars. We recruited up to 10 participants per focus group systematically using multiple strategies. Group 1 was interviewed first, group 14 last. Groups 6 and 10 were cancelled due to failing participation. Instead, groups 13 and 14 were recruited and interviewed. Participants were compensated with 500 DKK(66 Euro).
The focus groups were informally conducted using a standardized interview guide and a higher level of moderator involvement (10). Each interview lasted $2 \mathrm{~h}$. Participants first shared experiences and expectations of emergency medicine. After this, they discussed what would be the most important things to learn about acute patients as a medical student? This was followed by: Which clinical skills must newly graduated physicians master to be able to take care of emergency patients? Which conditions must newly graduated physicians master concerning initial diagnosis, examination and treatment? Finally, participants were asked to reflect on goals and objectives. During the last interviews, the core of objectives stabilized. No new themes or argumentations emerged, but new learning objectives were still suggested.

Interviews were recorded and discs stored with participants' consent. We anonymized participants during transcription. We coded the transcribed text using the software Ethnograph. The codebook was built up as a template (11) based on pre-existing knowledge, literature, and the first four focus group interviews. The final codebook contained 268 items, of which 196 were learning objectives. This article only reports on the part of the codebook consisting of the 196 objectives. Following content coding, we analysed by condensation, pattern coding, categorization, and displaying (12). We included a qualitative content analysis to detect patterns and augment interpretation (13). The researchers reached consensus on the codebook, difficult and critical parts of coding, categorization, and interpretation as a part of validation

Table 1

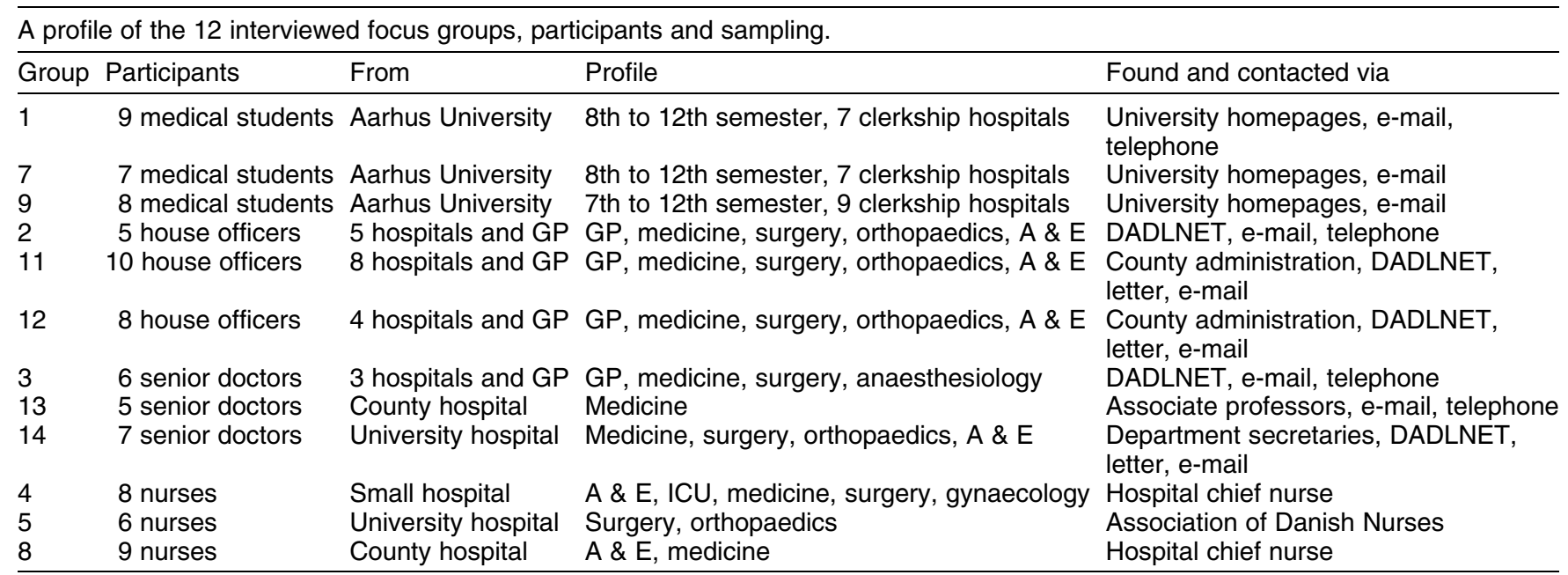

Group 1 was interviewed first, group 14 last. Groups 6 and 10 were cancelled due to failing participation. Instead, groups 13 and 14 were recruited and interviewed.

GP, General practice; A \& E, Accident and Emergency.

DADLNET, Association of Danish Doctors' web-based member catalogue. 
(12). Tapes and discs could be reanalyzed. Coding and search strategies were saved via Ethnograph.

We decided to include an objective in the undergraduate emergency medicine core curriculum, if participants agreed upon the objective. We defined agreement as: At least one focus group of both students, HOs, senior doctors, and nurses decisively pointed out the objective. We did not follow this rule concerning four objectives. In these four instances, one single participant could not accept an objective, which was definitely pointed out by the other focus group participants. As an example, one student did not find that setting up an i.v. drip was a core objective.

The ethical committee does not approve (or disapprove) descriptive curriculum research. The Danish data register (Datatilsynet) found that this research involved no sensitive or personal data. The head of department, Berit Eika, authorized the study.

\section{Results}

The focus groups discussed 196 learning objectives. Senior doctors pointed out 115 objectives. Nurses pointed out 104, students 100, and HOs 86 objectives. Participants agreed that newly graduated physicians should master the 43 objectives listed in Table 2: history taking, 21 clinical disorders, 15 practical skills, two specific diagnostic skills, two general diagnostic skills, and two leadership skills. Apart from these 43 objectives, participants gave very different priorities to knowledge about clinical disorders, practical clinical skills, communication, leadership, and 'the art of medicine' (Table3). 'The art of medicine' covers complexity of patient handling and integration of knowledge, skills and attitudes. Generally, students gave top priority to knowledge about clinical disorders. HOs prioritized practical skills. Nurses gave top priority to communication and leadership, whereas senior doctors primarily discussed the art of medicine' as core.

\section{Clinical disorders}

The focus groups agreed on 21 clinical disorders, where newly graduated physicians should master initial examination, diagnosis, and treatment (Table 2). Students particularly discussed knowledge of clinical disorders and found this most important. Nurses pointed to the same number of clinical disorders as students - 46 - but did not stress this part of the curriculum as much as students. We found large differences in which disorders the different stakeholders found important. Students and HOs, for example, pointed out delirium. But most participating senior doctors did not expect their $\mathrm{HO}$ to be able to handle a delirious patient. Students, HOs, and nurses, but not senior doctors pointed out objectives like burns, commotio, and acute alcohol intoxication.

Table 2

The undergraduate emergency medicine core curriculum agreed on by the focus group participants.

\begin{tabular}{l}
\hline History taking \\
\hline 21 clinical disorders and symptoms \\
Acute dyspnea and respiratory failure \\
Exacerbation of COPD \\
Severe asthma exacerbation \\
Acute pulmonary edema \\
Cardiac arrest \\
Acute myocardial infarction \\
Anaphylactic shock \\
Stupor and coma \\
Convulsions \\
Transient ischemic attack and stroke \\
Acute pain \\
Fever \\
Meningitis \\
Sepsis \\
Poisoning \\
Hypoglycaemia \\
Diabetic ketoacidosis \\
Acute abdomen \\
Bleeding \\
Hypovolaemic shock \\
Multi-trauma
\end{tabular}

15 practical skills

ABC, particularly

Secure patent airways

Manual bag ventilation (mask and tube)

Cardiac massage

The general physical examination, particularly

Auscultation of heart and lungs

Examination of abdomen

The general neurological examination

Examination the large joints

Insert intravenous lines

Set up an i.v. drip

Arterial blood gas sampling

Mix and administer an intravenous injection

Drop and aspire by a nasogastric tube

Catheterization of the bladder

Diagnostic skills

Interpret electrocardiograms (ECGs)

Interpret chest X-ray (CXR)

Diagnostic reasoning

Get a 'clinical impression' of the patient 
Table 3

\begin{tabular}{|c|c|c|}
\hline House officers & Nurses & Senior doctors \\
\hline Do ABC & Take a history & Be a good doctor \\
\hline Apply an oxygen mask & $\begin{array}{l}\text { Understand and talk } \\
\text { Danish }\end{array}$ & $\begin{array}{l}\text { Get a clinical } \\
\text { impression of patient }\end{array}$ \\
\hline $\begin{array}{l}\text { Insert percutaneous } \\
\text { intravenous line }\end{array}$ & $\begin{array}{l}\text { Talk to and brief the } \\
\text { patients' relatives }\end{array}$ & $\begin{array}{l}\text { Do the general } \\
\text { physical examination }\end{array}$ \\
\hline Set up an i.v. drip & $\begin{array}{l}\text { Communicate with } \\
\text { the team }\end{array}$ & $\begin{array}{l}\text { Interpret X-rays of } \\
\text { thorax (CXR) }\end{array}$ \\
\hline $\begin{array}{l}\text { Auscultation of heart } \\
\text { and lungs }\end{array}$ & $\begin{array}{l}\text { Lead the team during } \\
\text { the acute phase }\end{array}$ & $\begin{array}{l}\text { Interpret lab tests } \\
\text { (venous blood) }\end{array}$ \\
\hline $\begin{array}{l}\text { Drop and aspire by a } \\
\text { nasogastric tube }\end{array}$ & $\begin{array}{l}\text { Know one's own } \\
\text { limitations, ask for help }\end{array}$ & $\begin{array}{l}\text { Know clinical line of } \\
\text { thought, diagnostics }\end{array}$ \\
\hline Catheterize the bladder & Self-care and coping & Give a summary \\
\hline $\begin{array}{l}\text { Do a gynaecologic } \\
\text { examination }\end{array}$ & Empathy & Teamwork \\
\hline Do auroscopy & $\begin{array}{l}\text { Know principles of } \\
\text { sanitization }\end{array}$ & $\begin{array}{l}\text { Prioritize the HOs } \\
\text { simultaneous tasks }\end{array}$ \\
\hline
\end{tabular}

Senior doctor A: 'We have to try to teach them (STUDENTS) how - under the circumstances - you differentiate. How you match things, your clinical findings, the ECG, the lab-data and what else you have got. That you go more crosswise.

Interviewer:'Diagnostic reasoning?

Senior doctor A: 'Yes, drill it into their heads that things have to match. If we cannot make it match, something might not be quite right.

Senior doctor B: 'If not, it's like when layman is reading The Home Medical Adviser. Oh, that's the disease l've got!

Senior doctor C: 'In emergency medicine, we always work with likelihoods. We have made some observations that we piece together: This looks like that! and thinking like that is probably quite unfamiliar to the students, after all.

Senior doctor D: 'That's why, they want a diagnostic examination, an ultrasound or something. Well, it is nice to have. But I often experience that the students... It is black-white. If the blood sample doesn't say: This is it! An ultrasound, or an X-ray, or a consultant have said: There is an infiltrate. Well, then they feel left high and dry. But this is the core of medicine - the art! It's about likelihoods. It's most likely that the diagnosis is this and therefore we do that.

Senior doctor C: 'Well, it's called medical science and that sounds terribly exact. After all, most of what we do is craftsmanship. That's the difference. To be able to react on some things you have seen before. That's what it's all about.

\section{Practical skills}

Agreement between participants on practical skills was lower than on clinical disorders. In all, 91 practical skills were discussed, but participants only agreed upon 15 (Table2). During interviews, nurses and particularly HOs stressed the importance of including practical skills in the undergraduate emergency medicine core curriculum. In contrast, senior doctors often argued that practical skills could be postponed to the internship. When we counted how many practical skills participants included in the curriculum, we found that senior doctors included more practical skills than students, HOs, and nurses. Senior doctors pointed out 30 practical skills that HOs did not find to be core. Skills included only in senior doctors' core skills list were, for example, test for neck stiffness, anterior rhinoscopy, urine pregnancy test, urine microscopy, and set up a blood transfusion.

\section{Communication}

The ability to take a history was the only one of the 11 discussed communicative skills that was agreed upon 
by all participants. Nurses generally found communicative skills very important. Students hardly included any communicative skills as undergraduate objectives. Physicians included ascertain the patients' informed consent in the core curriculum. Nurses never mentioned this. Senior doctors all pointed out giving $a$ summary as a very important core objective, but were the only ones to do so. Senior doctors and nurses wanted newly graduated physicians to master communication with the team. HOs found this too difficult or impossible to learn pregraduately. Nurses included talking to and briefing patients' relatives. The other stakeholders strongly disagreed with peers and nurses on that topic.

\section{Other objectives}

Participants also discussed 30 other objectives in the fields of diagnostics, leadership, self-care and coping, and knowledge about principles of, for example sanitization, patient safety, preoperative preparation, Glasgow Coma Score, and i.v. fluid administration. Disagreement on these objectives was pronounced and participants only agreed on six of the 30 other objectives discussed. Senior doctors and nurses wanted to include most objectives in this category. Senior doctors often complained that HOs were too dependent on diagnostic examinations (See textbox). But, when asked if a newly graduated physician should be able to interpret a specific result, senior doctors actually often expected them to master it. Apart from ECG, HOs hardly occupied themselves with diagnostic examinations during interviews. Two specific diagnostic examinations were included in the undergraduate emergency medicine core curriculum (Table2). Intense discussions developed in all groups on general diagnostic skills. Two of these objectives were included in the core: diagnostic reasoning and getting a clinical impression of the patient. Participants recognized that these two objectives are difficult to teach and learn, but nevertheless found them the most essential in the curriculum (See textbox). Leadership skills were also intensely discussed and connected to the undergraduate emergency medicine core curriculum by physicians and particularly nurses. In contrast, students rarely discussed these skills. The two included objectives within this domain were that newly graduated physicians can lead the team during the initial acute phase and know their own limitations and ask for help (Table 2). Senior doctors and nurses uniformly demanded that newly graduated HOs could make the necessary acute decisions and prioritize tasks. Students and HOs postponed these objectives to internship.

\section{Discussion}

Focus groups involving medical students, HOs, senior doctors, and nurses could develop an undergraduate emergency medicine core curriculum. The defined objectives related to students' postgraduate training as HOs. However, participants had very different perspectives on the curriculum and gave different priorities to knowledge about clinical disorders, practical clinical skills, communication, leadership, and the art of medicine'. Our main conclusion is therefore a call for caution. We think that it is necessary to achieve local consensus on what is core curriculum and secure context and ownership to undergraduate emergency medicine core curricula before and during implementation. Focus groups could be one very practicable part of this.

The size of the undergraduate emergency medicine core curriculum can definitely be disputed. We only included 43 of the 196 suggested objectives. Ringsted et al. surveyed support among consultants for an assessment programme with 21 objectives covering first-year residency in anaesthesiology (14). They found excellent $(75 \%)$ support. This support could be connected to the fact that they developed such a small core curriculum. As mentioned in the introduction, the General Medical Council recommends that the core cover approximately two-thirds of the total undergraduate curriculum, but gives no answer to the question about the size of the core of undergraduate emergency medicine.

We confirmed that the decision of what to include as core objectives is also disputable. What one person found important was considered to be absolutely peripheral by another. What one focus group accepted unanimously, another rejected. The core objectives we found resembled but were not the same as other emergency medicine curricula (4-8). These curricula also differ. This has convinced us that the search for one 'correct' core is in vain. We question the assumption that a curriculum decided by an expert committee, however well designed, will be fully accepted by the other stakeholders, who are going to implement and live with it.

Involvement of a wider range of stakeholders can be part of a strategy to discuss and overcome different priorities and expectations. Decision-makers are 'natural' stakeholders, since they make the decisions. But who are the other stakeholders of undergraduate emergency medicine? We interviewed stakeholders, who were directly and daily involved in the clinical education of - and held a work relation to - newly graduated doctors. This included house officers (HOs) 
and senior doctors with HOs working as their 'front line.' We also interviewed nurses with HOs on call. This was based on the assumption that these nurses work closely together with HOs and often participate in their daily training. Nurses' attitudes and expectations to the results of undergraduate medical education thus have major practical implications for the working life of newly graduated physicians. Medical students were also included as educational stakeholders, since their education was explored. Other possible stakeholders could be faculty, patients, hospital administrators, professional organizations, clerkship directors, residency programme directors, and experts $(1,3)$. We recognize that the developed core curriculum reflects our choice of stakeholders. Implementation successes happen where goals and methods are modified to suit the needs and interests of the local staff (15). Local factors decide which stakeholders to involve.

If participants in a focus group perceive each other to be different, their willingness to discuss a topic together can be severely impaired (9). We therefore decided not to mix different stakeholders in a focus group. The choice of 10 participants per group was pragmatic and according to standards. We recruited participants systematically using multiple strategies. This is recommended as a strategy to avoid overreliance on accessible and elite informants (12). We had substantial difficulties recruiting senior doctors and had to give up focus group interviews with senior doctors at three hospitals due to failing participation (groups 6 and 10). From telephone conversations with senior doctors who did not participate, we found that the main reason for this usually was work overload and rarely disinterest in the topic. It is common practice to compensate focus group participants (9). We have no reason to believe that the amount of money (500 DKK) offered in this study could cause bias with respect to our purpose.

The focus group method has limitations, since the results are closely tied to the context. Purposeful sampling - as opposed to randomization - impairs generalizability. If one needs to generalize data, one has to conduct a larger survey that can support statistical conclusions. But focus group interviews are excellent for exploring and securing local support for a core curriculum. A new series of focus groups discussing the same questions could give a different result, since each focus group is unique with its own group dynamic that cannot be repeated (9). We therefore interviewed three times four focus groups. Thereby, we achieved a high level of data saturation, where objectives and argumentations were repeated. In con- clusion, running a series of focus group interviews to get access to stakeholders' experiences and attitudes on core objectives was feasible and can be used as a tool in the curriculum design process.

\section{Acknowledgements}

The County of Aarhus sponsored the project. We thank the many people who unselfishly helped us recruit the participants. Finally, we thank the focus group participants for sharing their perspectives with us.

\section{References}

1. Harden RM, Davis MH. AMEE Medical Education Guide, No. 5. The core curriculum with options or special study modules. Med Teacher 1995: 17(2): 125-48.

2. Cooper GM, Hutton P. Anaesthesia and the undergraduate medical curriculum. Br J Anaesth 1995: 74: 3-5.

3. World Federation for Medical Education. Basic medical education. WFME global standards for quality improvement. Denmark: University of Copenhagen, 2001.

4. Philips PS, Nolan JP. Training in basic and advanced life support in UK medical schools: questionnaire survey. $B M J$ 2001: 323: 22-3.

5. Cheung V, Critchley LAH, Hazlett C, Wong ELY, Oh TE. A survey of undergraduate teaching in anaesthesia. Anaesthesia 1999: 54: 4-12.

6. Rawlinson JN. Organising training for undergraduates and SHO's. J Accident Emerg Med 1999: 16: 69-71.

7. Tachakra S, Sivakumar A, McCabe M. Accident and emergency broadsheet. J Accident Emerg Med 1998: 15: 200-1.

8. Burdick WP, Jouriles NJ, D'Onofrio G, Kass LE, Mahoney JF, Restifo KM. Emergency medicine in undergraduate education. Acad Emerg Med 1998: 5(11): 1105-11.

9. Morgan DL. Focus groups as qualitative research. London: Sage, 1997.

10. Krueger RA. Developing questions for focus groups. Focus group kit 3. London: Sage, 1998.

11. Crabtree BF, Miller WL. Doing qualitative research. London: Sage, 1992.

12. Miles MB, Huberman AM. Qualitative data analysis. London: Sage, 1994.

13. Morgan DL. Qualitative content analysis: a guide to paths not taken. Qual Health Res 1993: 3(1): 112-21.

14. Ringsted C, Østergard D, Scherpbier A. Consultants' opinion on a new practice-based assessment programme for firstyear residents in anaesthesiology. Acta Anaesthesiol Scand 2002: 46: 1119-23.

15. Patton MQ. Qualitative evaluation and research methods. London: Sage, 1990.

Address:

Berit Eika

Enhed for Medicinsk Uddannelse

Århus Universitet

Universitetsparken

Bygning 611

8000 Århus C

Denmark 